\title{
Editorial
}

\section{La Revista Mexicana de Historia de la Educación: la renovación de un proyecto}

Desde hace muchos años las personas que han estado involucradas en el ámbito de la educación se han preocupado por dejar huella de la creación y el desarrollo de las instituciones educativas, de la labor desarrollada por los profesores e incluso de los logros de estudiantes brillantes. Pero la historia de la educación, entendida como una disciplina científica que busca explicar o comprender la forma en que los procesos educativos se llevan a cabo en distintos ámbitos de la sociedad y, especialmente, en las instituciones y los sistemas creados ex profeso para instruir, capacitar o educar a las nuevas generaciones, es en realidad reciente.

En México, tras los estudios de historia de la Pedagogía como los de Francisco Larroyo, que constituyen un antecedente importantísimo en la materia, el campo de la historia de la educación ha manifestado un creciente dinamismo a partir de los años setenta del siglo XX, mediante la realización de seminarios especializados en distintos centros de investigación e instituciones de educación superior, así como su inclusión como línea de estudio en distintos programas de posgrado.

El área de la educación se ha ido haciendo cada vez más presente en las reuniones académicas dedicadas a la historia, mientras que el enfoque histórico ha ganado terreno con fuerza en aquellas abocadas a las ciencias de la educación. A partir de 1986, los historiadores de la educación han contado en México con un espacio para encontrarse y debatir sus avances de investigación en el Encuentro Nacional de Historia de la Educación, que a partir de 1994 adquirió un nivel internacional. Asimismo, se han organizado actividades internacionales, de entre las cuales destacan el Congreso Iberoamericano de Historia de la Educación (CIHELA) y la International Standing Conference for History of Education (ISCHE). A partir de los años ochenta del siglo pasado se han estrechado los vínculos y el intercambio con pares de otros países, lo que se ha manifestado especialmente en la aparición de una cantidad importante de publicaciones colectivas. 
En este dinamismo del campo no ha estado ausente la intención de abrir espacios de análisis y debate de la historia de la educación a través de publicaciones seriadas, algo que ha sido preocupación constante de la Sociedad Mexicana de Historia de la Educación desde su creación en 2002, primero con un Anuario coordinado por la doctora Oresta López (2005), y luego por la revista Memoria, conocimiento y utopía dirigida por la doctora María Esther Aguirre de 2006 a 2008.

Con la aparición de la Revista Mexicana de Historia de la Educación renovamos la idea de crear una publicación propia del campo de la historia de la educación en donde se pueda leer cómo los hombres y las mujeres hemos enseñado y aprendido formas de ser y hacer a lo largo de la historia y a lo ancho del mundo con propósitos, estrategias y resultados a veces similares, a veces cambiantes; un espacio en donde exista la generación de conocimiento, el debate de las ideas, el rastreo de las fuentes, el ensayo de las metodologías y el intercambio de las experiencias, en fin, un sitio de revisión periódica de todo aquello de lo que tenemos que echar mano los historiadores en el reto de comprender y explicar la educación en su dimensión temporal y en su interrelación con las esferas de lo social y lo cultural, de los procesos económicos y de los sistemas políticos en toda su complejidad y magnitud. En algunas ocaciones algunos procesos parecerían más importantes que otros, por lo que no se intenta marcar límites de entrada, por el contrario, se busca dar lugar a las diferentes interrogantes, enfoques y técnicas que desde su rigurosidad nutran a la historia de la educación como campo de estudio.

Para llevar a cabo estas metas hemos seleccionado el formato digital, el cual nos permite aprovechar los recursos tecnológicos al alcance para dar a conocer con mayor facilidad y agilidad el uso de las diversas fuentes y metodologías (como por ejemplo, de imágenes o videos, entre otras), antes limitadas por las publicaciones impresas $-\mathrm{y}$ todo lo que éstas implican-, que necesariamente daban prioridad al examen de fuentes documentales o a la descripción que los propios autores pueden hacer de otro tipo de huellas del pasado y del presente. Éstos, claro, siempre editan y editarán las fuentes, pero el formato juega un papel muy importante en las posibilidades de expresión de los historiadores. Por otra parte, la publicación digital, siempre y cuando sea gratuita, permite la circulación del conocimiento con rapidez y amplía de manera significativa el número de posibles lectores. La inclusión futura de artículos en varios idiomas, también se deriva del afán de llegar a más lectores y de incluir las investigaciones de historiadoras e historiadores de la educación de distintas latitudes, para poner un granito de arena en la creación y expansión de las redes académicas.

Inauguramos estos propósitos con artículos que expresan la pluralidad de temáticas, enfoques teóricos y metodologías que actualmente se utilizan en la historia de la educación. El número que hoy presentamos abre con un artículo de María del Mar Pozo, en el que se estudian las láminas escolares en España para ver de qué manera y qué tanto este recurso 
didáctico favoreció la formación de identidades nacionales en los niños españoles. La comprensión de las relaciones entre la ciudadanía y la escuela se analiza por medio de la cultura material de la escuela.

Le sigue un estudio de María Guadalupe Cedeño que centra su atención en el Obispado de Michoacán, que se ubicó en el occidente de México, para analizar cómo la educación durante el periodo colonial no se limitaba a los aspectos religiosos, sino que se conformó de diferentes modelos dependiendo del tipo de población específica que intervenían en ellos. Un estudio reducido espacialmente permite acercarse a las huellas de las prácticas educativas para observar diferenciaciones en la educación según los actores que la impulsaron y los que la recibieron.

El tercer artículo está escrito por Juan Pedro Galván, joven autor que muestra cómo la Pedagogía tuvo un lugar importante en la rica producción editorial que se desarrolló en México durante la segunda mitad del siglo XIX y principios del siglo XX, al analizar en tres casos cómo la prensa coadyuvó a difundir, entre los profesores y la sociedad letrada, propósitos y modelos educativos que irían influyendo en el creciente sistema escolar.

La circulación del pensamiento pedagógico fue muy importante tanto en México como en muchos otros países de América Latina durante el siglo XIX y principios del siglo XX. La edición de libros y revistas fue relevante, pero quizás más aún la celebración de conferencias pedagógicas e higiénicas. En su artículo, Amalia Nivón analiza los debates que se llevaron a cabo acerca de los indios y su educación dentro del liberalismo y la construcción de los Estados nacionales en el caso del Primer Congreso Pedagógico Centro Americano, realizado en Guatemala en 1893.

La atención en los educadores y las ideas pedagógicas pasa hacia los historiadores de la educación y los programas de formación de maestros con el artículo de Marta Maria Chagas de Carvalho, quien analiza el cambio de paradigma que se experimenta en la historia de la educación en Brasil al dejar de ver a la escuela como institución disciplinaria para observar los dispositivos espaciales y temporales y las relaciones intersubjetivas que sostienen la cultura escolar, mediante el examen de la experiencia del Centro de Memoria de la Educación de la Universidad de São Paulo. Con un punto de vista diferente, más centrado en la historia de las ideas y de la ciencia, Carmen Betti analiza la formación de la historia de la educación como una disciplina autónoma en Italia a lo largo de dos siglos, destacando tanto las contribuciones de los autores italianos como las influencias recibidas desde otros países europeos o de los Estados Unidos.

Los dos últimos artículos incluidos en este número de la revista posan su mirada en algunas fuentes importantes para la historia de la educación. En su artículo, Carlos Escalante nos habla de las posibilidades de análisis que pueden tener los historiadores de la educación al trabajar con fuentes tales como las cartillas de alfabetización, que fueron 
diseñadas para la Campaña Nacional contra el Analfabetismo que se impulsó en México entre los años 1944 y 1946.

Los historiadores no sólo consultamos fuentes, sino que también nos ocupamos de la preservación de la memoria de los proyectos educativos. En el texto que cierra este número, Norma Ramos y Armando René Espinosa relatan los propósitos y resultados de un proyecto que busca localizar y preservar la memoria fotográfica de las escuelas en San Luis Potosí, México.

Con este número zarpa el barco hacia un largo viaje a tierras desconocidas y puertos que, aunque sean familiares, mirarán con nuevos ojos entre las memorias, los conocimientos y las utopías.

Alicia Civera Cerecedo

Zinacantepec, México, enero de 2013. 